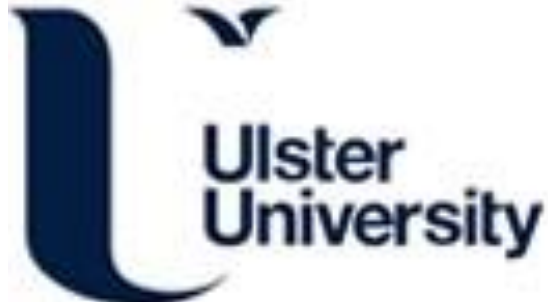

\section{Effect of storage pressure on transient combustion of hydrogen released through a pipe to the atmosphere}

Bragin, M., \& Molkov, V. (2011). Effect of storage pressure on transient combustion of hydrogen released through a pipe to the atmosphere. In Proceedings of the Sixth International Seminar on Fire and Explosion Hazards (pp. 473-480). Research Publishing.

Link to publication record in Ulster University Research Portal

\section{Published in:}

Proceedings of the Sixth International Seminar on Fire and Explosion Hazards

Publication Status:

Published (in print/issue): 01/01/2011

\section{Document Version}

Publisher's PDF, also known as Version of record

\section{General rights}

Copyright for the publications made accessible via Ulster University's Research Portal is retained by the author(s) and / or other copyright owners and it is a condition of accessing these publications that users recognise and abide by the legal requirements associated with these rights.

\section{Take down policy}

The Research Portal is Ulster University's institutional repository that provides access to Ulster's research outputs. Every effort has been made to ensure that content in the Research Portal does not infringe any person's rights, or applicable UK laws. If you discover content in the Research Portal that you believe breaches copyright or violates any law, please contact pure-support@ulster.ac.uk. 


\title{
Effect of Storage Pressure on Transient Combustion of Hydrogen Released Through a Pipe to the Atmosphere
}

\author{
Bragin, M.V.* and Molkov, V.V. \\ Hydrogen Safety Engineering and Research Centre (HySAFER), University of \\ Ulster, Shore Road, Newtownabbey, BT37 0QB, UK \\ *Corresponding author email: mv.bragin@ulster.ac.uk
}

\begin{abstract}
The main objective of this work is to study the effect of storage pressure on spontaneous ignition of hydrogen at sudden release from a high pressure vessel and its transient combustion. This paper describes modelling and large eddy simulation (LES) of spontaneous ignition dynamics emerging from a tube into a semi-confined space. The comparison between 147 and 700 bar storage pressures is given in terms of flow velocity, temperature and hydrogen and hydroxyl mole fractions. It is demonstrated that while for the lower pressure the combusting cocoon is broken, for the higher pressure it remains intact. The difference in process dynamics is attributed to the wider high temperature area by the time the mixture reaches the end of the tube.
\end{abstract}

KEYWORDS: hydrogen, high-pressure release, spontaneous ignition, large-eddy simulation, transient combustion

\section{NOMENCLATURE LISTING}

\begin{tabular}{|l|l|l|l|}
\hline$U_{C S}$ & $\begin{array}{l}\text { Speed of the contact surface, } \\
\text { separating gases (m/s) }\end{array}$ & \multicolumn{2}{l|}{ Subscripts } \\
\hline$T_{\text {air }}$ & temperature of air $(\mathrm{K})$ & air & air \\
\hline$T_{H 2}$ & temperature of hydrogen (K) & H2 & hydrogen \\
\hline$P_{\text {air }}$ & pressure of air $(\mathrm{Pa})$ & $\mathrm{CS}$ & contact surface \\
\hline$P_{\text {SHair }}$ & $\begin{array}{l}\text { pressure of shock heated air } \\
\text { behind shock wave }(\mathrm{Pa})\end{array}$ & SHair & shock heated air \\
\hline$a$ & speed of sound (m/s) & ECH2 & expansion cooled hydrogen \\
\hline Greek & & & \\
\hline$\gamma$ & ratio of specific heats & & \\
\hline
\end{tabular}

\section{INTRODUCTION}

Since pioneering work of Wolanski and Wojcicki in 1972 [1] number of studies were undertaken to get insight into the phenomenon of spontaneous ignition of highpressure hydrogen during sudden release. Experimental confirmation of spontaneous ignition during releases to the atmosphere through a pipe was obtained in $[2,3,4]$, where the process was facilitated by various extension tubes and attachments positioned downstream of a burst disk. Analysis of these data has been presented in $[5,6]$. Some studies were focused on initiation of spontaneous ignition in extension 
pipe with a limited number of experiments aimed at investigating what happens with an ignited mixture once it exits from the pipe into the atmosphere $[2,6,7,8]$. It was previously shown in [6] that for the experimental setup of Mogi et al. [4] (pressure $147 \mathrm{bar}$, pipe length $185 \mathrm{~mm}$, diameter $5 \mathrm{~mm}$ ) the transition to the sustained jet flame is largely dependent on the initial jet formation stage. The applicability of the LES model has been confirmed by the fact that simulations reproduced experimental observation that the combusting cocoon is torn into upstream and downstream flame regions. Current paper studies the effect of storage pressure on the dynamics of spontaneous ignition in the pipe and transitional combustion of the erupted flame in the atmosphere for two pressures 147 and 700 bar.

\section{THE LES MODEL}

The large eddy simulation (LES) model applied in this study is essentially the same as in [6] and employs the RNG model [9] for subgrid-scale modelling of turbulence and the Eddy-Dissipation-Concept (EDC) model by Magnussen [10] to model the reaction rate. The EDC model incorporates detailed Arrhenius chemical kinetics in turbulent flames. The mass diffusivity of the mixture is modelled using kinetic theory with default values for the Lennard-Jones characteristic length and energy parameter for the individual species. The viscosity and the specific heat at constant pressure of the mixture have been evaluated using mass-weighted mixing laws. For the individual species in the mixture these properties have been evaluated using Sutherland's law and fifth order polynomials in temperature respectively. The comparison of numerical simulations with experimental data $[3,4]$ was given in [6].

\section{NUMERICAL DETAILS}

The computational domain and grid were taken from [6] to facilitate the comparison of results. It consisted of three main parts: high-pressure storage, release tube with 5 $\mathrm{mm}$ internal diameter and $185 \mathrm{~mm}$ length, and outside area. Both high-pressure storage and outside area were taken such as to prevent flow disturbances from reaching their boundaries.

A zoom up slice of the meshed computational domain in the vicinity of the pipe exit is presented in Fig. 1. The grid was adapted as the process evolved to keep the characteristic cell size in the region of anticipated combustion of the order of $400 \mu \mathrm{m}$. The total number of control volumes increased from $261 \mathrm{k}$ to $718 \mathrm{k}$ as a result of grid refinement during the simulation.

Non-slip impermeable adiabatic boundary conditions were used on all walls. Where the mesh is too coarse to resolve the laminar sub-layer, the near-wall treatment of the flow is carried according to the law-of-the-wall similar to [6].

Initial conditions for high pressure storage were pressure $700 \mathrm{bar}$, temperature $300 \mathrm{~K}$ and the mole fraction of hydrogen equal to 1 . The pipe and the outside area were filled with air ( 0.23 mass fraction of oxygen and 0.77 of nytrogen) at pressure 1.01 bar and temperature $300 \mathrm{~K}$. Similarly to the previous study [6], high-pressure zone extended from the storage reservoir to one pipe diameter $(5 \mathrm{~mm})$ downstream, i.e. high-pressure hydrogen was also initially present in the first $5 \mathrm{~mm}$ of the tube. Non-reflecting "far field" boundary conditions were set in the downstream and radial directions in the 
atmosphere. Imaginary non-inertial rupture disk separating high pressure hydrogen and atmospheric pressure air was removed instantly and shock wave was allowed to propagate.

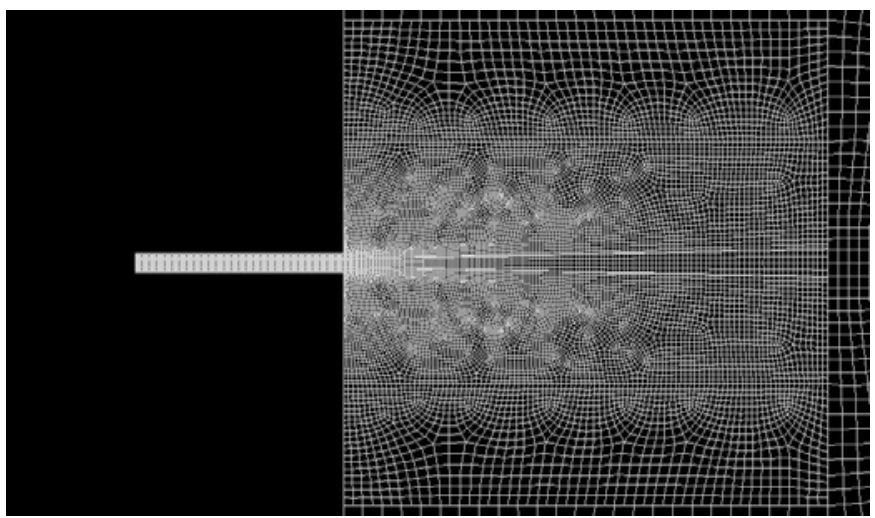

Figure 1. The grid refined in the vicinity of the pipe exit into the atmosphere.

The problem was simulated using general-purpose CFD package FLUENT 6.3.26, which realises control-volume based finite-difference method. The solver used explicit linearisation of the governing equations with explicit method for solution of linear equation set. A second order upstream scheme was applied for flow discretisation. The four step Runge-Kutta algorithm was employed for advancement of solution in time. The time step was determined from Courant-Friedrichs-Lewy condition, where the CFL number was equal to 0.5 to ensure stability.

\section{RESULTS AND DISCUSSION}

When the imaginary rupture-disk is removed, a shock wave starts to propagate in air from an initial contact surface location thus compressing and heating it. Thus, we have hot air on one side of the contact surface and cold hydrogen on another side. We can use classical gasdynamic shock tube problem to validate the shock generated by the discontinuity in our simulations. The analytical solution to the problem [11] relates the initial pressure ratio on discontinuity to the velocity $U_{C S}$ of the contact surface, pressure $P_{\text {air }}$ and temperature $T_{\text {air }}$ of compressed air, and finally temperature of the expanding hydrogen $T_{\mathrm{H} 2}$ upstream of the contact surface. The equations are presented below:

$$
\begin{aligned}
& \frac{P_{H 2}}{P_{\text {air }}}=\frac{P_{\text {SHair }}}{P_{\text {air }}}\left[1-\frac{\left(\gamma_{\text {air }}-1\right)\left(a_{\text {air }} / a_{L}\right)\left(P_{\text {SHair }} / P_{\text {air }}-1\right)}{\sqrt{2 \gamma_{\text {air }}\left(2 \gamma_{\text {air }}+\left(\gamma_{\text {air }}+1\right)\left(P_{\text {SHair }} / P_{\text {air }}-1\right)\right)}}\right]^{-2 \gamma_{\mathrm{H} 2} /\left(\gamma_{\mathrm{H} 2}-1\right)} \\
& U_{\text {CS }}=a_{\text {air }}\left(\frac{P_{\text {SHair }}}{P_{\text {air }}}-1\right) \sqrt{\frac{2}{\gamma_{\text {air }}\left[\left(\gamma_{\text {air }}+1\right) P_{\text {SHair }} / P_{\text {air }}+\left(\gamma_{\text {air }}-1\right)\right]}}
\end{aligned}
$$




$$
\begin{aligned}
& \frac{T_{\text {SHair }}}{T_{\text {air }}}=\frac{1+\frac{\gamma_{\text {air }}-1}{\gamma_{\text {air }}+1} \cdot \frac{P_{\text {SHair }}}{P_{\text {air }}}}{1+\frac{\gamma_{\text {air }}-1}{\gamma_{\text {air }}+1} \cdot \frac{P_{\text {air }}}{P_{\text {SHair }}}} \\
& \frac{T_{E C H 2}}{T_{H 2}}=\left(\frac{P_{\text {SHair }}}{P_{H 2}}\right)^{\left(\gamma_{H 2}-1\right) / \gamma_{H 2}}
\end{aligned}
$$

Pressure of the shock heated air behind the shock wave $P_{\text {SHair }}$ can be calculated from Eq. 1. Equation 2 gives the speed of the contact surface $U_{S W}$ separating gases. Temperature of air behind the shock wave $T_{\text {SHair }}$ is given by Rankine-Hugoniot Eq. 3 . Temperature of cold expanded hydrogen $T_{C E H 2}$ upstream of the contact surface is given by the isentropic relation Eq. 4.

Parameters of the flow and resulting shock wave are summarized in Table 1 . The difference in parameters between 1D theory and 3D simulations is likely attributed to the averaging over the control volume in simulations.

\begin{tabular}{|l|c|c|c|c|}
\hline \multicolumn{1}{|c|}{ Data origin } & $\boldsymbol{U}_{\mathbf{C S}}, \mathbf{m} / \mathbf{s}$ & $\boldsymbol{T}_{\text {air }}, \mathbf{K}$ & $\boldsymbol{P}_{\text {air }}$, bar & $\boldsymbol{T}_{\mathbf{H} 2}, \mathbf{K}$ \\
\hline Simulation 147 bar & 1725 & 1260 & 24 & 180 \\
\hline 1D theory 147 bar & 1704 & 1370 & 28.7 & 188 \\
\hline Simulation 700 bar & 2150 & 3030 & 48 & 127 \\
\hline 1D theory 700 bar & 1983 & 3137 & 57.7 & 146 \\
\hline
\end{tabular}

Table 1. Comparison of simulated shock parameters against 1D theory [11].

Dynamics of temperature, velocity, hydrogen and hydroxyl mole fractions are shown in Fig. 2 and Fig. 3. The field of view in all frames was kept constant, where the pipe length shown corresponds to $66.5 \mathrm{~mm}$, and the outside area is $148 \mathrm{~mm}$ in length and $130 \mathrm{~mm}$ in width perpendicular to the jet axis. All snapshots represent a vertical 2D cross-section of the flow across the pipe axis. The maximum and minimum values in each series were fixed in order to lock the relation between colours and corresponding parameters in all frames. Minimum and maximum values in each set of frames were fixed to $0-2400 \mathrm{~K}$ for temperature, $0-3000 \mathrm{~m} / \mathrm{s}$ for velocity, $0-1$ for hydrogen mole fraction, and 0.001-0.01 for hydroxyl mole fraction. If values fall out of these limits, they are coloured according to the colour of limits - red for upper and blue for lower. The first frame in time series corresponds to $96 \mu$ s from the burst-disk rupture. For ease of understanding the time scales of the transition process the reference time was set to $0 \mu \mathrm{s}$ at this moment and Figures show this relative time. 


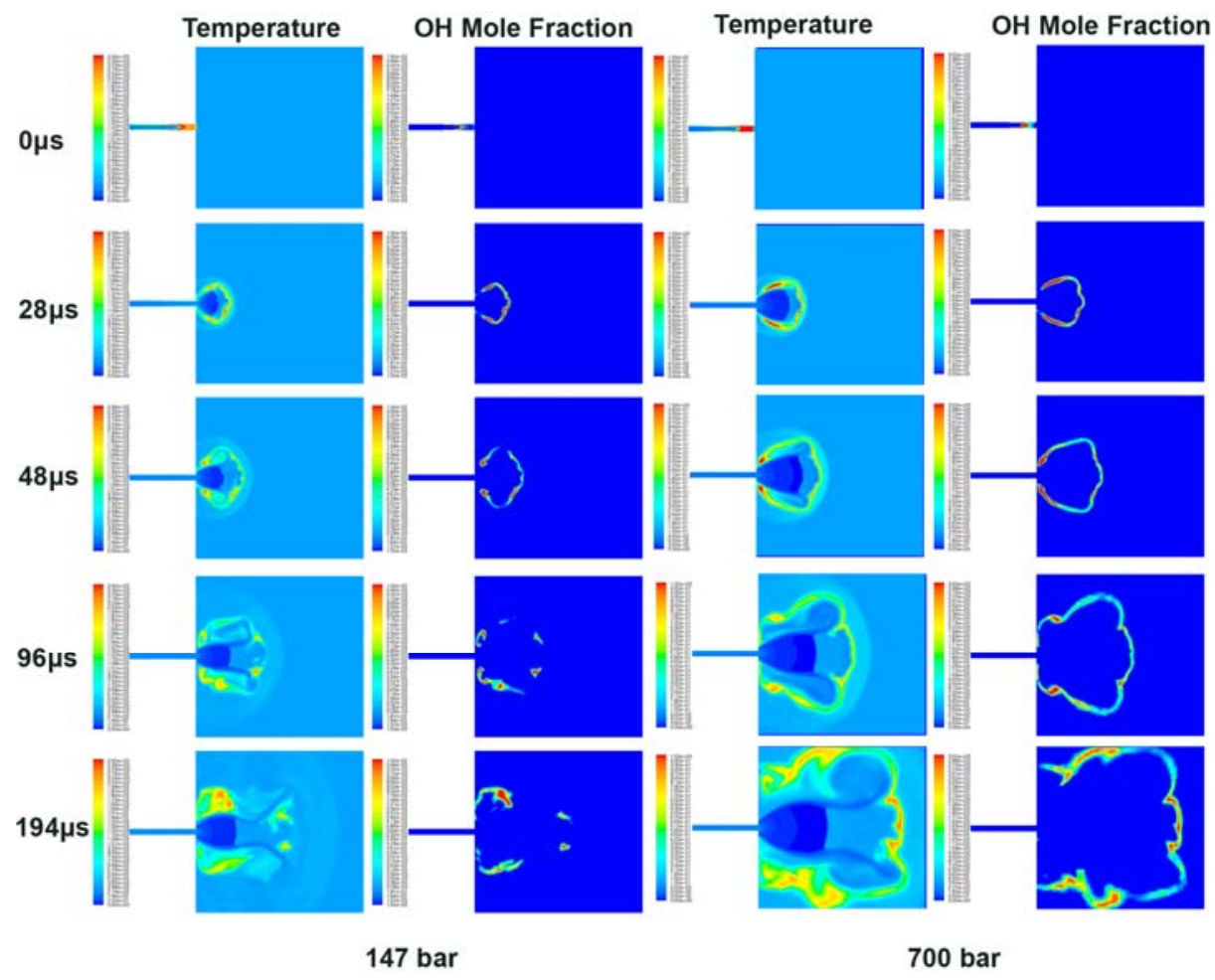

Figure 2. Dynamics of temperature and hydroxyl mole fraction for release from hydrogen storage pressure $147 \mathrm{bar}$ (left) and $700 \mathrm{bar}$ (right).

For the case of 700 bar, hydrogen is expanding faster upon exit from the tube. The size of the final barrel is almost a factor of 2 compared to that of a 147 bar case. Generally, the distribution of hydrogen and velocity looks similar (Fig. 3). Thus, the increase of pressure results in some scaling up of the characteristic dimensions of the problem.

In terms of temperature and hydroxyl mole fraction, however, we see similar dynamics, but significant change in the shape of the flame front (indicated by the hydroxyl mole fraction profiles). Unlike the case of 147 bar (Fig. 2, left), the combusting cocoon for 700 bar case (Fig. 2, right) is not broken by the annular flow. Although it can be noticed that from $100 \mu$ s the combustion becomes weaker in the area downstream of the unfolding annular vortex, the cocoon survives the initial stage without being broken in two parts. 


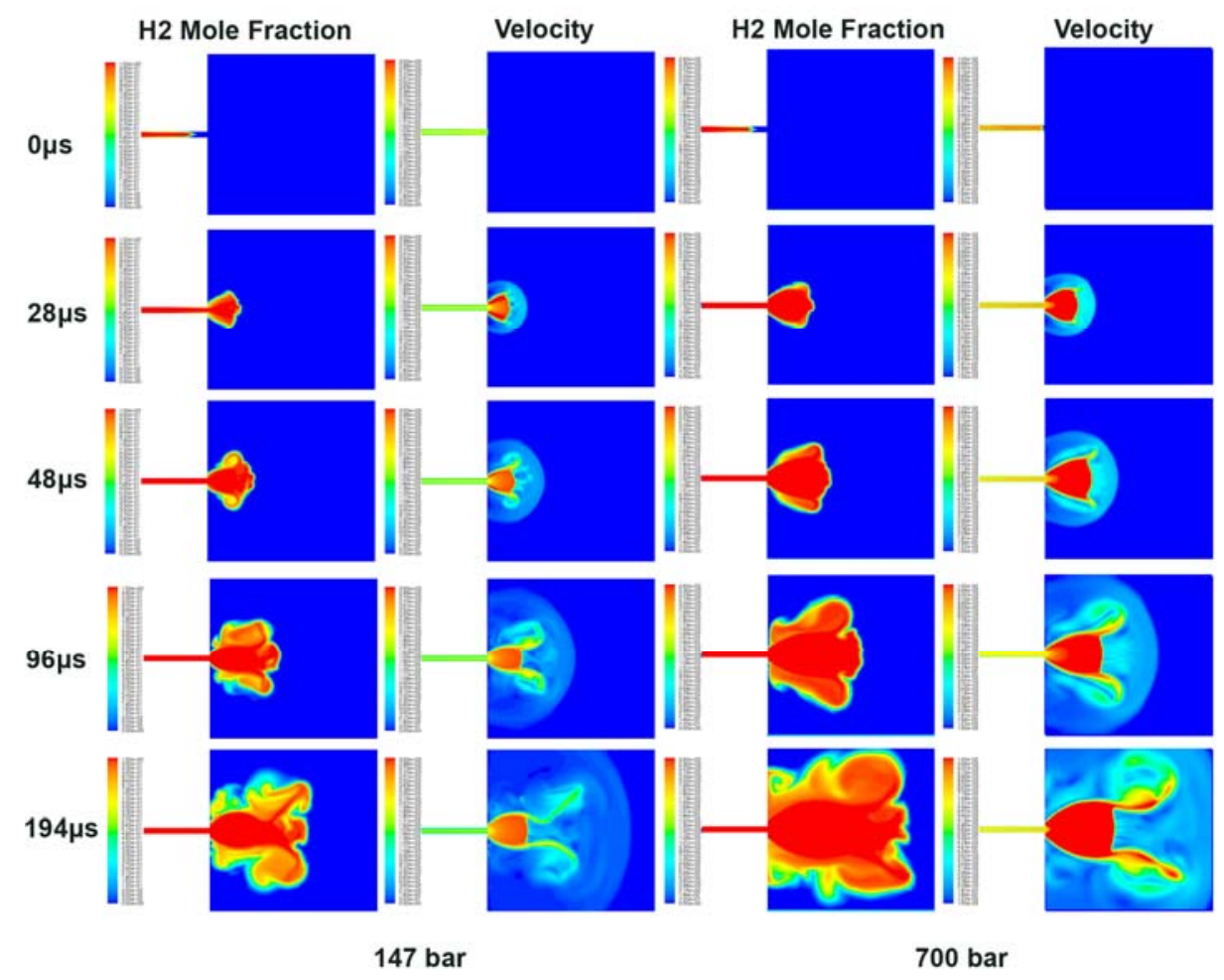

Figure 3. Dynamics of velocity and hydroxyl mole fraction for release from hydrogen storage pressure $147 \mathrm{bar}$ (left) and $700 \mathrm{bar}$ (right).

The difference in combustion dynamics can be explained using parameters indicated in Table 1. For the higher pressure 700 bar case the temperature of compressed air is factor of two higher than for the lower pressure case, while the temperature of hydrogen is only reduced by $40 \mathrm{~K}$ upstream of the contact surface. By the end of the pipe, the layer of shock-heated air has higher temperature (see Fig. 4), which allows it to survive the expansion. Please note, that the temperature scale is different from Fig. 2 and 3 . As the shock heated air leaves the pipe, it creates thicker combusting cocoon, having higher temperature and stronger chemical reaction.

Current work studies the effect of pressure on combustion dynamics. Further studies should address the effect of orifice size on combustion dynamics and validate the model capability to represent the blow-off for orifice diameter less than $0.1 \mathrm{~mm}$.

The model used in current work is capable of capturing the essential features of the flow and combustion dynamics and can be used to develop innovative pressure relief devices for hydrogen economy. 


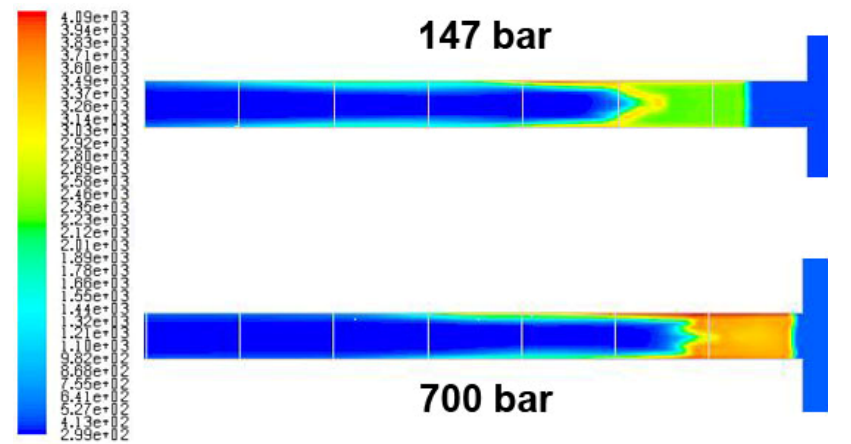

Figure 4. Temperature field in the pipe for hydrogen storage pressure 147 bar (top) and 700 bar (bottom).

\section{CONCLUSIONS}

The increase of hydrogen storage pressure from 147 to 700 bar results in stronger leading shock wave heating compressed air above $3000 \mathrm{~K}$. The higher temperature and larger areas of hydrogen mixing with air creates more favourable conditions for combustion. In particular, the combustion cocoon is not broken-up by the annual flow at pressure 700 bar.

\section{REFERENCES}

1. Wolanski, P. and Wojcicki, S., "Investigation into the mechanism of the diffusion ignition of a combustible gas flowing into an oxidizing atmosphere," Proceedings of the Combustion Institute 14: 1217-1223 (1972).

2. Dryer, F.L., Chaos, M., Zhao, Z., Stein, J.N., Alpert, J.Y. and Homer, C.J., "Spontaneous ignition of pressurized releases of hydrogen and natural gas into air," Combustion Science and Technology 179(4): 663-694 (2007).

3. Golub, V.V., Baklanov, D.I., Golovastov, S.V., Ivanov, M.F., Laskin, I.N., Saveliev, A.S., Semin, N.V. and Volodin, V.V., "Mechanisms of high-pressure hydrogen gas self-ignition in tubes," Journal of Loss Prevention in the Process Industries 21(2): 185-198 (2008).

4. Mogi, T., Kim, D., Shiina, H. and Horiguchi, S., "Self-ignition and explosion during discharge of high-pressure hydrogen," Journal of Loss Prevention in the Process Industries 21(2): 199-204 (2008).

5. Molkov, V., "Preface to Special Issue on Hydrogen Safety," Journal of Loss Prevention in the Process Industries, 21(2): 129-130 (2008).

6. Bragin, M. and Molkov, V., "Physics of spontaneous ignition of high-pressure hydrogen release and transition to jet fire," Proc. 3rd International Conference on Hydrogen Safety, Ajaccio, 2009, Paper 265.

7. Yamada, E., Watanabe, S., Hayashi, A.K., Tsuboi, N., "Numerical analysis on autoignition of a high-pressure hydrogen jet spouting from a tube," Proceedings of the Combustion Institute 32(2): 2363-2369 (2009). 
8. Wen, J.X., Xu, B.P., Tam, V.H.Y., "Numerical study on spontaneous ignition of pressurized hydrogen release through a length of tube," Combustion and Flame 156(11): 2173-2189 (2009).

9. Yakhot, V. and Orszag, S., "Renormalization group analysis of turbulence. I. Basic theory," Journal of Scientific Computing 1: 3-51 (1986).

10. Magnussen, B.F, "On the structure of turbulence and a generalized eddy dissipation concept for chemical reactions in turbulent flow," Proc. 19th American Institute for Aeronautics and Astronautics Aerospace Science Meeting. St. Louis, Missouri, USA (1981).

11. Liepmann, H.W. and Roshko, A., Elements of gasdynamics, John Wiley \& Sons, New York, 1957, p.81. 